\title{
Effect of Feed Rate on Structure of Hyperbranched Polymers Formed by Self-Condensing Vinyl Polymerization in Semibatch Reactor
}

\author{
Kuo-Chung Cheng, ${ }^{*}, \dagger$ Tsu-Hwang Chuang, ${ }^{\dagger}$ Jun-Shang Chang, ${ }^{\dagger}$ Wenjeng Guo, ${ }^{\dagger}$ and \\ Wei-Fang Su
}

Department of Chemical Engineering and Biotechnology, National Taipei University of Technology, Taipei, 106, Taiwan, and Department of Materials Science \& Engineering,

National Taiwan University, Taipei, 106, Taiwan

Received March 28, 2005; Revised Manuscript Received July 10, 2005

\begin{abstract}
Hyperbranched polymers (HBPs) formed by a self-condensing vinyl polymerization (SCVP) of copolymerization of $\mathrm{AB}^{*}$ monomers slowly added into trifunctional $\mathrm{C}_{3} *$ cores under various feed rates were investigated by a kinetic model. The dependences of average molecular weight, polydispersity, degree of branching, and number of structural units of the hyperbranched polymers on the feed rate were calculated by a generating function method. It was found that the final polydispersity index (PDI) can be attained below 1.5 by a slow addition of $\mathrm{AB}^{*}$ at a feed rate parameter, $\phi$, less than 2 . While the $\mathrm{AB}^{*}$ monomers fed quickly, the system with a lower content of the $\mathrm{C}_{3} *$ cores results in a broader molecular weight distribution. A high degree of branching, about 0.66 , can be achieved by addition of $\mathrm{AB}^{*}$ monomers into a small amount of $\mathrm{C}_{3} *$ cores at $\phi$ lower than 10 .
\end{abstract}

\section{Introduction}

Synthesis of polymers with novel architectures has become a major research interest. Because dendimers and hyperbranched polymers exhibit very different characteristic features from those of the linear polymers, such as relatively low viscosity, high solubility, and having a large amount of pending or peripheral or side functional groups. ${ }^{1-7}$ Therefore, many potential applications - tougheners, molecular sensors, rheology modifiers, drug delivery system, nonlinear optical (NLO) materials, macromolecular building blocks, and nanotechnology - all have been suggested. ${ }^{8-10}$

The hyperbranched polymers (HBPs) have a less regular structure than the dendrimers. However, compared with the complicated and expensive procedures for the synthesis of dendrimers, they can be prepared by a simpler one-pot polycondensation of $\mathrm{AB}_{\mathrm{g}}$-type monomers in which $g$ is greater than one. ${ }^{11}$

Frechet et al. reported that HBPs can be prepared by a self-condensing vinyl polymerization (SCVP). ${ }^{12} \mathrm{It}$ involves $\mathrm{AB}^{*}$ monomer, such as $p$-(chloromethyl)styrene, consisting a vinyl group $\mathrm{A}$ and an initiating group $B^{*} \cdot{ }^{13-17}$ The chain reactions is the active $B^{*}$ reacting with the double bond $\mathrm{A}$ of another monomer; then a dimer is formed with one group $\mathrm{A}$ and two active groups: $B^{*}$ and $A^{*}$. The new active center $A^{*}$ converted from the group A by reacting with $\mathrm{B}^{*}$ can also react with the double bond of any other molecules and form a branch point on the resulting larger molecule. Consequently, the hyperbranched polymers can be synthesized under further polymerization. Recently, selfcondensing vinyl polymerization has been further applied to various types of living/controlled polymerization, such as nitroxide-mediated radical polymerization, atom transfer radical polymerization, group transfer polymerization, and ring-opening polymerization. ${ }^{3,18-21}$

Unfortunately, according to the experimental results and theory calculations, the molecular weight distribu-

National Taipei University of Technology.

$\doteqdot$ National Taiwan University.

* Corresponding author: E-mail: gordon@ntut.edu.tw. tion, MWD, of the hyperbranched polymers via the selfcondensing vinyl polymerization is extremely broad at high conversion, and the maximum degree of branching, $\mathrm{DB}$, is only about $0.5 .^{13,14}$ It was reported that the polydispersity index (PDI) of the final products can be reduced by reacting $\mathrm{AB}^{*}$ monomers with a little multifunctional cores, but the DB decreases with increasing of cores. In previous modeling calculation, by adding the cores with higher reactivity, the PDI of HBPs can be further reduced, and the DB can be kept at about $0.46 .^{22}$ Muller and co-workers also reported that the DB of HBPs made by SCVP is increased up to 0.67 by using multifunctional cores and adding monomers slow enough so that the monomer molecules only reacted with the cores. $^{15}$ In their calculation, the feed rate of $\mathrm{AB}^{*}$ monomers is exponentially increased in time such that the monomer concentration is constant, and the reaction between monomers $\mathrm{AB}^{*}$ is neglected. It was found that, at a low amount of cores, the PDI of HBPs is independent of the particular form of the feed rate.

In a practical semibatch polymerization process, the reactor is often operated at a certain constant feed rate. Therefore, it is necessary to investigate the dependence of the feed rate on the structure parameters of the hyperbranched polymers. In a previous work, we found that both of the DB and PDI of the HBPs can be changed by the feed rate of $\mathrm{AB}_{2}$ monomers into multifunctional cores. ${ }^{23}$ In this study, the generating function method will be further applied to the self-condensing vinyl polymerization of multifunctional $\mathrm{C}_{3} *$ cores with $\mathrm{AB}^{*}$ monomers in a semibatch reactor. This kinetic model will be adopted to investigate the dependence of the feed rate on the structure parameters, such as molecular weight, polydispersity, and degree of branching of the hyperbranched polymers.

\section{Kinetic Model of Self-Condensing Vinyl Polymerization of Monomers $\mathrm{AB}^{*}$ with Multifunctional Cores $\mathbf{C}_{3}$ *}

The self-condensing vinyl polymerization (SCVP) involves monomers $\mathrm{AB}^{*}$ with core $\mathrm{C}_{3}$, of which active 
group $\mathrm{B}^{*}$ and $\mathrm{C}^{*}$ can initiate the polymerization of vinyl group, $\mathrm{A}$; then the $\mathrm{A}$ become a new active group, $\mathrm{A}^{*}$. The $\mathrm{B}^{*}$ and $\mathrm{C}_{3} *$ are converted into " $\mathrm{b}$ " and "c" product groups, respectively: ${ }^{22}$

$$
\begin{aligned}
& \mathrm{A}+\mathrm{B}^{*} \stackrel{k_{\mathrm{AB}^{*}}}{\longrightarrow} \mathrm{A}^{*}+\mathrm{b} \\
& \mathrm{A}+\mathrm{C}^{*} \stackrel{k_{\mathrm{AC} *}}{\longrightarrow} \mathrm{A}^{*}+\mathrm{c}
\end{aligned}
$$

Furthermore, the group $\mathrm{A}^{*}$ can also react with vinyl group A and becomes a group "a":

$$
\mathrm{A}+\mathrm{A}^{*} \stackrel{k_{\mathrm{AA}}^{*}}{\longrightarrow} \mathrm{A}^{*}+\mathrm{a}
$$

where $k_{\mathrm{AB}^{*}}, k_{\mathrm{AC} *}$, and $k_{\mathrm{AA}^{*}}$ are the reaction rate constants and $k_{\mathrm{AB}^{*}}=k_{\mathrm{AC}}=k_{\mathrm{AA}^{*}}$.

Although the effects of intramolecular cyclization on the structures of the hyperbranched polymers are important for nonlinear polymerization systems, which were discussed before, ${ }^{24-26}$ in this study, we focus on the effect of the feed rate of monomers on the structure of polymers and assume that the reaction is bimolecular; that is, there are no cyclization occurs during polymerization. ${ }^{22,23}$

First, a vector $\mathbf{E}$ is defined to characterize the molecule $\langle\mathrm{E}\rangle$ :

$$
\mathbf{E}=\left(e_{1}, e_{2}, e_{3}, e_{4}, e_{5}, e_{6}, e_{7}, e_{8}, e_{9}, e_{10}, e_{\mathrm{w}}\right)
$$

where $e_{J}$ represents the number of structural units, $G(J)$, on a molecule $\langle\mathrm{E}\rangle$, and $e_{\mathrm{w}}$, equal to $e_{11}$, is the molecular weight of the molecule $\langle\mathrm{E}\rangle$. In this study, both of the molecular weights of monomers $\mathrm{AB}^{*}$ and $\mathrm{C}_{3} *$ are set to be one. The reactions between molecules are

$$
\left\langle\mathrm{E}^{\prime}\right\rangle+\left\langle\mathrm{E}^{\prime \prime}\right\rangle \stackrel{k_{i}}{\longrightarrow}\left\langle\mathrm{E}^{\prime}+\mathrm{E}^{\prime \prime}+\mathrm{L}_{i}\right\rangle, \quad i=1,2, \ldots, 16
$$

where $\left\langle\mathrm{E}^{\prime}+\mathrm{E}^{\prime \prime}+\mathrm{L}_{i}\right\rangle$ is the molecule formed by combining $\left\langle\mathrm{E}^{\prime}\right\rangle$ with $\left\langle\mathrm{E}^{\prime \prime}\right\rangle$ in the $i$ th reaction, and

$$
\begin{gathered}
\mathrm{L}_{i}=\left(l_{1}, l_{2}, \ldots, l_{10}, 0\right) \\
l_{J}=-\delta\left(b_{i 1}, J\right)-\delta\left(b_{i 2}, J\right)+\delta\left(b_{\mathrm{i} 3}, J\right)+\delta\left(b_{i 4}, J\right), \\
J=1,2, \ldots, 10
\end{gathered}
$$

in which $\delta\left(b_{i j}, J\right)$ is Kronecker delta such that

$$
\delta\left(b_{i j}, J\right)=1, \quad \text { for } b_{i j}=J
$$

and

$$
\delta\left(b_{i j}, J\right)=0, \text { for } b_{i j} \neq J
$$

The corresponding parameters, $b_{i j}, J$, and $k_{i}$, in eqs 5

\begin{tabular}{|c|c|c|c|c|c|c|}
\hline $\begin{array}{llllll}b_{11} & b_{12} & b_{13} & b_{14} & k_{1}\end{array}$ & & 1 & 1 & 3 & 2 & $\mathrm{k}_{\mathrm{AB}^{*}}$ \\
\hline $\begin{array}{llllll}b_{21} & b_{22} & b_{23} & b_{24} & k_{2}\end{array}$ & & 1 & 3 & 3 & 4 & $\mathrm{k}_{\mathrm{AB}^{*}}$ \\
\hline $\begin{array}{llllll}b_{31} & b_{32} & b_{33} & b_{34} & k_{3}\end{array}$ & & 1 & 5 & 3 & 6 & $\mathrm{k}_{\mathrm{AB}^{*}}$ \\
\hline $\begin{array}{lllll}b_{41} & b_{42} & b_{43} & b_{44} & k_{4}\end{array}$ & & 1 & 3 & 3 & 5 & $\mathrm{k}_{\mathrm{AA}^{*}}$ \\
\hline $\begin{array}{lllll}b_{51} & b_{52} & b_{53} & b_{54} & k_{5}\end{array}$ & & 1 & 4 & 3 & 6 & $\mathrm{k}_{\mathrm{AA}^{*}}$ \\
\hline $\begin{array}{llllll}b_{61} & b_{62} & b_{63} & b_{64} & k_{6}\end{array}$ & & 2 & 1 & 4 & 2 & $\mathrm{k}_{\mathrm{AB}^{*}}$ \\
\hline $\begin{array}{llllll}b_{71} & b_{72} & b_{73} & b_{74} & k_{7}\end{array}$ & & 2 & 3 & 4 & 4 & $\mathrm{k}_{\mathrm{AB}^{*}}$ \\
\hline $\begin{array}{lllll}b_{81} & b_{82} & b_{83} & b_{84} & k_{8}\end{array}$ & & 2 & 5 & 4 & 6 & $\mathrm{k}_{\mathrm{AB}^{*}}$ \\
\hline $\begin{array}{lllll}b_{91} & b_{92} & b_{93} & b_{94} & k_{9}\end{array}$ & & 2 & 3 & 4 & 5 & $\mathrm{k}_{\mathrm{AA}} \mathrm{A}^{*}$ \\
\hline$b_{101} b_{102} b_{103} b_{104} k_{10}$ & $=$ & 2 & 4 & 4 & 6 & $\mathrm{k}_{\mathrm{AA}^{*}}$ \\
\hline$b_{111} b_{112} b_{113} b_{114} k_{11}$ & & 1 & 7 & 3 & 8 & $3 \mathrm{k}_{\mathrm{AC}}$ \\
\hline$b_{121} b_{122} b_{123} b_{124} k_{12}$ & & 1 & 8 & 3 & 9 & $2 \mathrm{k}_{A C^{*}}$ \\
\hline$b_{131} b_{132} b_{133} b_{134} k_{13}$ & & 1 & 9 & 3 & 10 & $\mathrm{k}_{\mathrm{AC}}{ }^{*}$ \\
\hline$b_{141} b_{142} b_{143} b_{144} k_{14}$ & & 2 & 7 & 4 & 8 & $3 \mathrm{k}_{\mathrm{AC}} *$ \\
\hline$b_{151} b_{152} b_{153} b_{154} k_{15}$ & & 2 & 8 & 4 & 9 & $2 \mathrm{k}_{\mathrm{AC}}$ \\
\hline$b_{161} b_{162} b_{163} b_{16}$ & & 2 & 9 & 4 & 10 & $\mathrm{k}_{\mathrm{AC}}^{*}$ \\
\hline
\end{tabular}
and 6 are shown in Table 1 , and the reactions between various structural units or isomers are described in the Appendix. A dimensionless number of isomers, a ratio of the reaction rate constant, and a scaled time are defined as follows

$$
\begin{gathered}
{[E]=N(E) / N_{0}} \\
k_{i}^{\prime}=k_{i} / k_{0} \\
\tau=t k_{0}\left(N_{0} / V_{0}\right)
\end{gathered}
$$

where $N(E)$ is the number of isomers of the molecule $\langle\mathrm{E}\rangle ; N_{0}$ and $V_{0}$ are the initial number and volume of core
Table 1. Parameters of $b_{i j}$ and $k_{i}$

$\mathrm{C}_{3} *$, respectively. $k_{0}$ is the arbitrary reference rate constant, and $t$ is the reaction time.

For a constant-density reaction system in which $\mathrm{AB}^{*}$ monomers are slowly added at molar rate $F_{\mathrm{AB}^{*}}$ to a reactor containing cores $\mathrm{C}_{3}{ }^{*}$. A mole balance on $\mathrm{AB}^{*}$ yields

$$
\mathrm{d} N_{\mathrm{AB}^{*}} / \mathrm{d} t=F_{\mathrm{AB}^{*}}+V(t) r_{\mathrm{AB}^{*}}
$$

where $r_{\mathrm{AB}}$ is reaction rate of $\mathrm{AB}^{*}$ and $V(t)$ is the reaction volume. Substituting the rate law in eq 7 gives

$$
\begin{array}{r}
N_{0} \frac{\mathrm{d}\left[\mathrm{AB}^{*}\right]}{\mathrm{d} t}=F_{\mathrm{AB}^{*}}+\frac{N_{0}^{2}}{V(t)}\left\{-k_{\mathrm{AB}^{*}}\left[\mathrm{AB}^{*}\right]\left[\mathrm{AB}^{*}\right]-\right. \\
k_{\mathrm{AB}^{*}}[\mathrm{AB} *]\left[\mathrm{A}^{*} \mathrm{~B}^{*}\right]-k_{\mathrm{AB}}[\mathrm{AB} *][\mathrm{aB} *]- \\
k_{\mathrm{AA}^{*}}\left[\mathrm{AB}^{*}\right]\left[\mathrm{A}^{*} \mathrm{~B}^{*}\right]-k_{\mathrm{AA}^{*}}[\mathrm{AB} *]\left[\mathrm{A}^{*} \mathrm{~b}\right]- \\
3 k_{\mathrm{AC}^{*}}\left[\mathrm{AB}^{*}\right]\left[\mathrm{C}_{3}^{*}\right]-2 k_{\mathrm{AC}^{*}}\left[\mathrm{AB}^{*}\right]\left[\mathrm{C}_{2}^{*} \mathrm{c}\right]- \\
\left.k_{\mathrm{AC} *}\left[\mathrm{AB}^{*}\right]\left[\mathrm{C}^{*} \mathrm{c}_{2}\right]-k_{\mathrm{AB}^{*}}[\mathrm{Ab}][\mathrm{AB} *]\right\}
\end{array}
$$

For the reactor is being filled, the volume, $V$, varies with time. Assuming the specified volume of the $\mathrm{AB}^{*}$, $v_{\mathrm{AB}}$, is the same as that of the $\mathrm{C}_{3}{ }^{*}$, thus the $V(t)$ can be rewritten as

$$
V(t)=V_{0}+F_{\mathrm{AB}^{*} v_{\mathrm{AB}}^{*}} t=V_{0}+F_{\mathrm{AB}^{*}} \frac{V_{0}}{N_{0}} t=V_{0}(1+\phi \tau)
$$

where the feed rate parameter $\phi=F_{\mathrm{AB}} * V_{0} / N_{0}{ }^{2} k_{0}$. Therefore, eq 8 becomes

$$
\begin{array}{r}
\frac{\mathrm{d}\left[\mathrm{AB}^{*}\right]}{\mathrm{d} \tau}=\phi+\frac{1}{1+\phi \tau}\left\{-k_{1}{ }^{\prime}\left[\mathrm{AB}^{*}\right]\left[\mathrm{AB}^{*}\right]-\right. \\
k_{2}{ }^{\prime}\left[\mathrm{AB}^{*}\right]\left[\mathrm{A}^{*} \mathrm{~B}^{*}\right]-k_{3}{ }^{\prime}\left[\mathrm{AB}^{*}\right]\left[\mathrm{aB}^{*}\right]-k_{4}{ }^{\prime}\left[\mathrm{AB}^{*}\right]\left[\mathrm{A}^{*} \mathrm{~B}^{*}\right]- \\
k_{5}{ }^{\prime}\left[\mathrm{AB}^{*}\right]\left[\mathrm{A}^{*} \mathrm{~b}\right]-k_{11}\left[\mathrm{AB}^{*}\right]\left[\mathrm{C}_{3}{ }^{*}\right]-k_{12}\left[\mathrm{AB}^{*}\right]\left[\mathrm{C}_{2}{ }^{*} \mathrm{c}\right]- \\
\left.k_{13}{ }^{\prime}\left[\mathrm{AB}^{*}\right]\left[\mathrm{C}^{*} \mathrm{c}_{2}\right]-k_{6}{ }^{\prime}[\mathrm{Ab}]\left[\mathrm{AB}^{*}\right]\right\}
\end{array}
$$

According to eq 5, a mole balance on the other isomer $\langle\mathrm{E}\rangle$ is shown as follows:

$$
\begin{array}{r}
\frac{\mathrm{d}[\mathrm{E}]}{\mathrm{d} \tau}=\frac{1}{1+\phi \tau_{i=1}} \sum_{\mathrm{E}^{\prime}+\mathrm{E}^{\prime \prime}+\mathrm{L}_{i}=\mathrm{E}}^{16} k_{i}^{\prime}\left\{\sum_{\text {all } \mathrm{E}^{\prime}}\left(\left[\mathrm{E}^{\prime}\right]\left[\mathrm{E}^{\prime \prime}\right] p^{\prime}{ }_{i 1} \mathrm{p}^{\prime \prime}{ }_{i 2}\right)-[\mathrm{E}] p_{i 2} \sum_{\text {all } \mathrm{E}^{\prime}}\left[\mathrm{E}^{\prime}\right] p^{\prime}{ }_{i 1}\right\}
\end{array}
$$


and $\sum_{\text {all } E}$ denotes the sum over all possible values of vector $\mathbf{E}$, and $p_{i j}=e_{J}$ for $b_{i j}=J$ as shown in eqs 4-6 and Table 1. For example, a molecule $\langle\mathrm{E}\rangle$ can be formed by a combination of molecules $\left\langle\mathrm{E}^{\prime}\right\rangle$ and $\left\langle\mathrm{E}^{\prime \prime}\right\rangle$ through the reaction mechanism 2 indicated in the Appendix; then $i=2, b_{21}=1$, and $p_{21}^{\prime}=e_{1} ; b_{22}=3$, and $p_{22}^{\prime \prime}=e_{3}$. Note that $e_{1}$ and $e_{3}$ denote the number of structural units $\mathrm{G}(1)$ in molecule $\left\langle\mathrm{E}^{\prime}\right\rangle$ and $\mathrm{G}(3)$ in $\left\langle\mathrm{E}^{\prime \prime}\right\rangle$, respectively, and the reaction rate is proportional to the product of the $\mathrm{G}(1)$ concentration, $\left[\mathrm{E}^{\prime}\right] p_{21}^{\prime}$, and $\mathrm{G}(3)$ concentration, $\left[\mathrm{E}^{\prime \prime}\right] p^{\prime \prime}{ }_{22}$. The positive terms on the right side of eq 11 give the total generation rates of isomer $\langle\mathrm{E}\rangle$ formed from two smaller molecules, $\left\langle\mathrm{E}^{\prime}\right\rangle$ and $\left\langle\mathrm{E}^{\prime \prime}\right\rangle$, through possible mechanisms and combinations. And the negative terms denote the disappearance rates of the isomer $\langle\mathrm{E}\rangle$, which reacted with other molecule, $\left\langle\mathrm{E}^{\prime}\right\rangle$, and becomes a larger one.

Equations 10 and 11 cannot be solved directly, but it can be transformed into finite ordinary differential equations using a generating function. ${ }^{27}$ First, eqs 10 and 11 were multiplied by dummy variables and summed over $\mathbf{E}$ to yield a rate equation of the generation function. Furthermore, the zero, first, and second moment of the molecular weight distribution (MWD) and the concentration of units of hyperbranched polymers were related to the generating function. Finally, the profiles of the average molecular weights of HBPs and the fractions of the structural units were calculated on the basis of the set of ordinary differential equations. The algorithm was described in the previous papers. ${ }^{23,28}$

\section{Results and Discussion}

In the self-condensing vinyl polymerization of monomers $\mathrm{AB}^{*}$ with core $\mathrm{C}_{3}{ }^{*}$, the relationship between the final number-average degree of polymerization (DP) and the monomer ratio can be derived as follows: ${ }^{22,23}$

\section{$\overline{\mathrm{DP}_{\mathrm{n}}}=$}

total no. of monomers added into reactor

total no. of molecules at full conversion of group A

$$
\begin{gathered}
=\frac{N_{\mathrm{f}}\left(\mathrm{AB}^{*}\right)+N_{0}}{N_{\mathrm{f}}\left(\mathrm{AB}^{*}\right)+N_{0}-N_{\mathrm{f}}\left(\mathrm{AB}^{*}\right)} \\
=1+\frac{1}{\lambda}
\end{gathered}
$$

where $\lambda=N_{0} / N_{\mathrm{f}}\left(\mathrm{AB}^{*}\right)$ and $N_{\mathrm{f}}\left(\mathrm{AB}^{*}\right)$ is the final number of monomers $\mathrm{AB}^{*}$ added in to the reactor; $N_{0}$ is the initial number of core $\mathrm{C}_{3} *$. In the self-condensing vinyl polymerization, once a group of " $\mathrm{A}$ " has reacted, the total number of molecules will be reduced by one. Therefore, at full conversion of group $\mathrm{A}$, the number of molecules equals the initial number of core $\mathrm{C}_{3} *$. Accordingly, the final number-average molecular weight of HBPs can be controlled by adding various ratios of core monomers, and it increases with the number of the added $\mathrm{AB}^{*}$.

The influences of the parameter of feed rate of monomers $\mathrm{AB}^{*}, \phi$, on polydispersity index (PDI) at different ratios of cores, $\lambda$, are plotted in Figures $1-3$. In the case of $\lambda=0.01$, Figure 3 , at a low feed rate, for example $\phi=0.1$, the PDI increases with the degree of the polymerization and then reaches a limiting value,

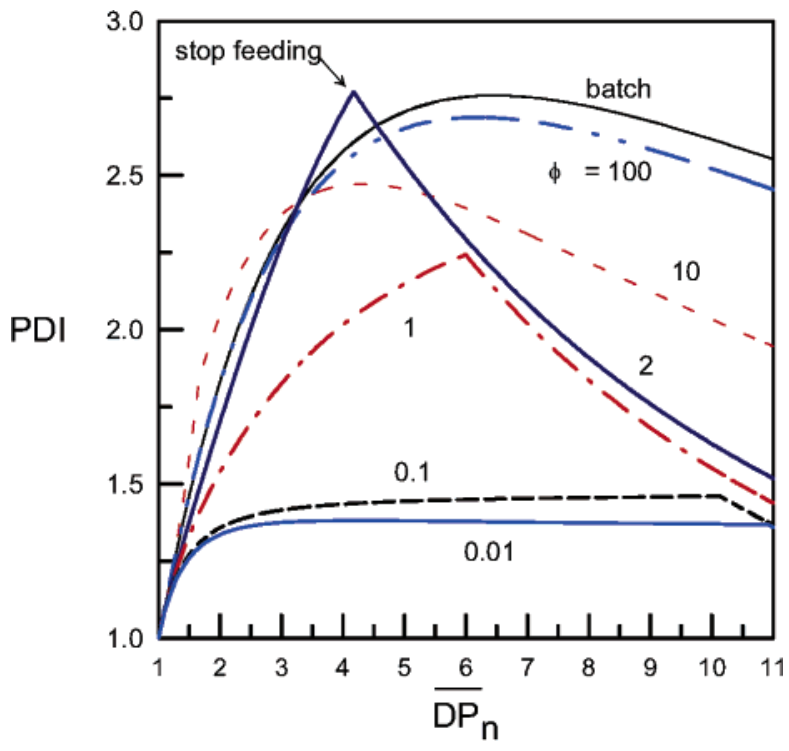

Figure 1. Dependence of the polydispersity on degree of polymerization at various feed rates $(\lambda=0.1)$.

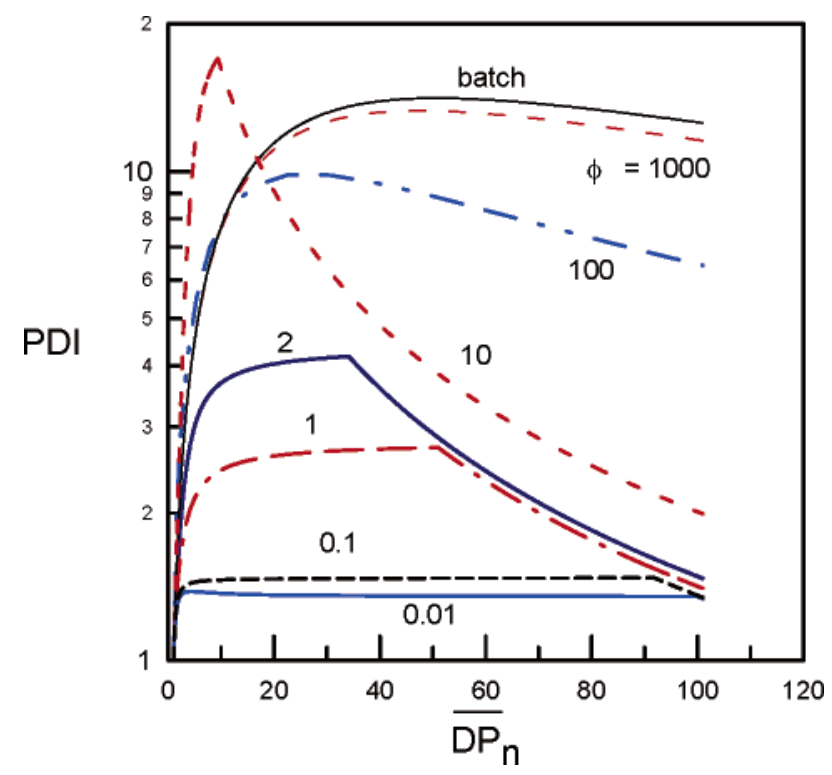

Figure 2. Dependence of the polydispersity on degree of polymerization at various feed rates $(\lambda=0.01)$.

about 1.47. After stopping the feed of $\mathrm{AB}^{*}$ monomers, the DPI is further reduced to 1.34 at the complete consumption of $\mathrm{A}^{*}$ groups. On the other hand, when the $\mathrm{AB}^{*}$ monomers were added quickly, for example $\phi=$ 1000 , the profile of the PDI is close to the result of the batch system, in which the $\mathrm{AB}^{*}$ monomers and $\mathrm{C}_{3} *$ cores were fed into a reactor at the same time. It is obvious that the higher feed rate causes the boarder distribution of molecular weight of the hyperbranched polymers.

There are two types of the growing molecules in the SCVP of $\mathrm{AB}^{*}$ monomers with $\mathrm{C}_{3} *$ cores. The first one is the molecule with a focal unit $\mathrm{Ab} \sim$. It is easy to combine two large molecules into an even larger one, which then leads to a broad molecular weight distribution. Another type includes a reacted core unit on the molecule. Because the molecules containing the core unit have no reactive group $\mathrm{A} \sim$, they cannot be combined with each 


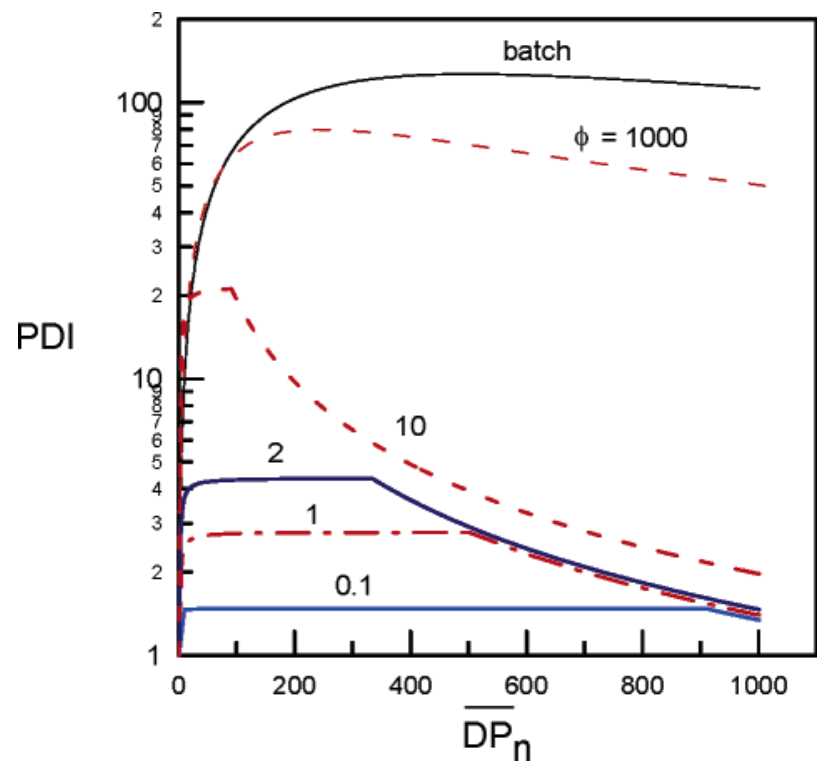

Figure 3. Dependence of the polydispersity on degree of polymerization at various feed rates $(\lambda=0.001)$.

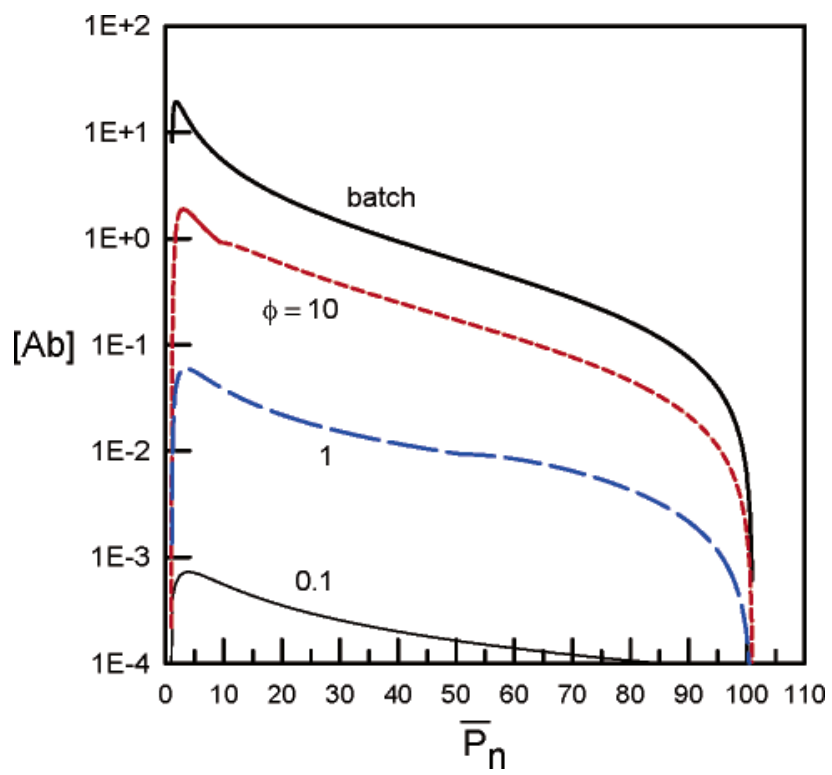

Figure 4. Changes of the number of focal units during polymerization at various feed rates $(\lambda=0.01)$.

other to form a larger one. While the $\mathrm{AB}^{*}$ monomers is fed slowly into the reactor, for the system with $\lambda=0.01$, the probabilities of the formation of the focal units $\mathrm{A}-\mathrm{b} \sim$ become low, but dendritic units $\mathrm{c}_{3}$ increase as shown in Figures 4 and 5. Therefore, under slow feeding, such as $\phi=1$ or 0.1 , the major growth of the hyperbranched polymers is contributed to the combinations of the molecule having a core unit with $\mathrm{AB}^{*}$ monomer added gradually; thus, the PDI is kept at a low value.

However, with a higher adding rate of $\mathrm{AB}^{*}, \phi=10$ in Figures 2 and 6 , the initial growth of the weightaverage DP is quicker than that of the batch system. At $\phi=10$, the probability is high for the combination of the molecule having a focal unit $\mathrm{Ab} \sim$ with the other molecule containing a core unit. It will cause a broader molecular weight distribution. After stopping the addi-

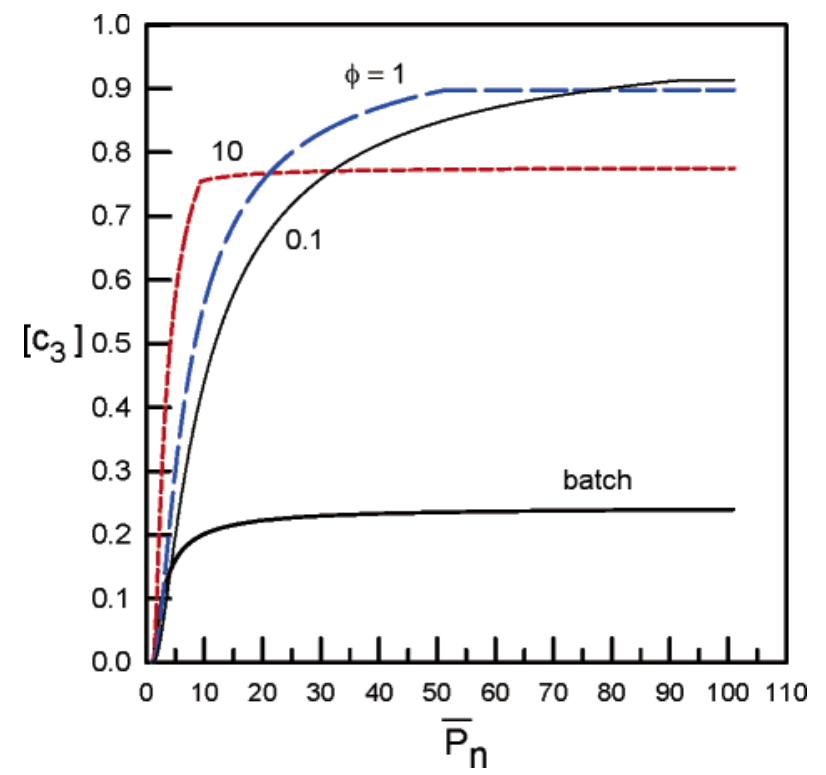

Figure 5. Changes of the number of dendritic units $c_{3}$ during polymerization at various feed rates $(\lambda=0.01)$.

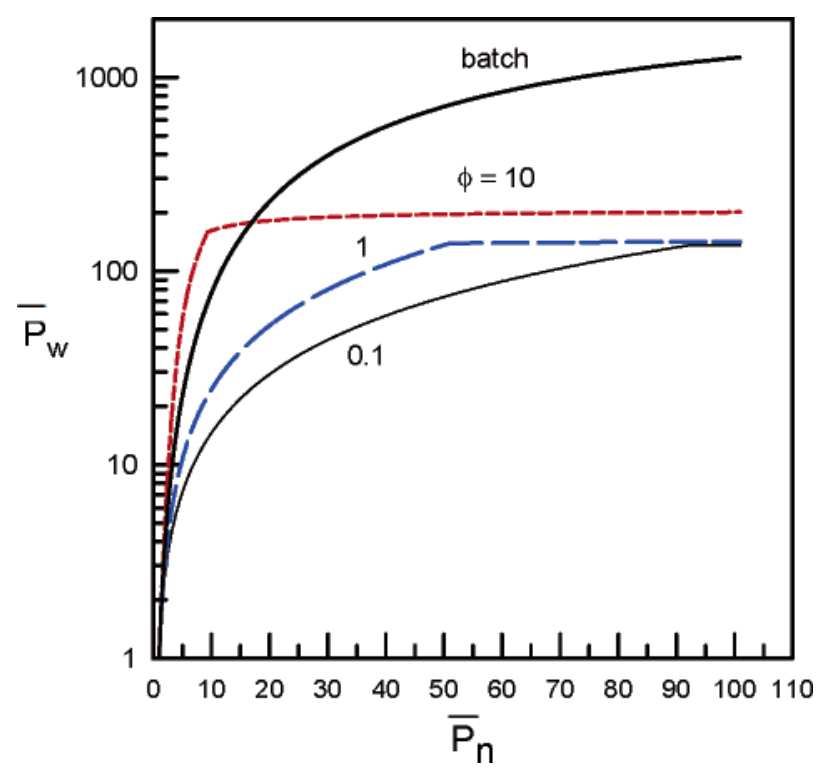

Figure 6. Weight-average degree of polymerization profile changed with the feed rate $(\lambda=0.01)$.

tion of $\mathrm{AB}^{*}$, the growth of weight-average DP of HBPs will be retarded as shown in Figure 6 .

Furthermore, the final PDI changed with the feed rate, $\phi$, and core/monomer ratio, $\lambda$, are summarized in Figure 7. For the systems with $\lambda=0.001-0.1$, the final PDI can be attained below 1.5 by a slow addition, $\phi<$ 1. In contrary, while the $\mathrm{AB}^{*}$ monomers fed at quick rate, the system with a lower content of the $\mathrm{C}_{3} *$ cores results in a broader molecular weight distribution. This result is similar to the $\mathrm{AB}_{2}$ reacted with $C_{3}$ cores discussed before. ${ }^{23}$ In the case of high value of $\lambda$, there are a large number of molecules with a core unit formed at early stage; thus, the growth of polymers will be dominated by the reaction of the molecule containing a core unit with $\mathrm{A} * \mathrm{~B}$ monomers, and the MWD of the HBPs becomes narrower.

The degree of branching, DB, is a very important structural parameter in characterizing the hyper- 


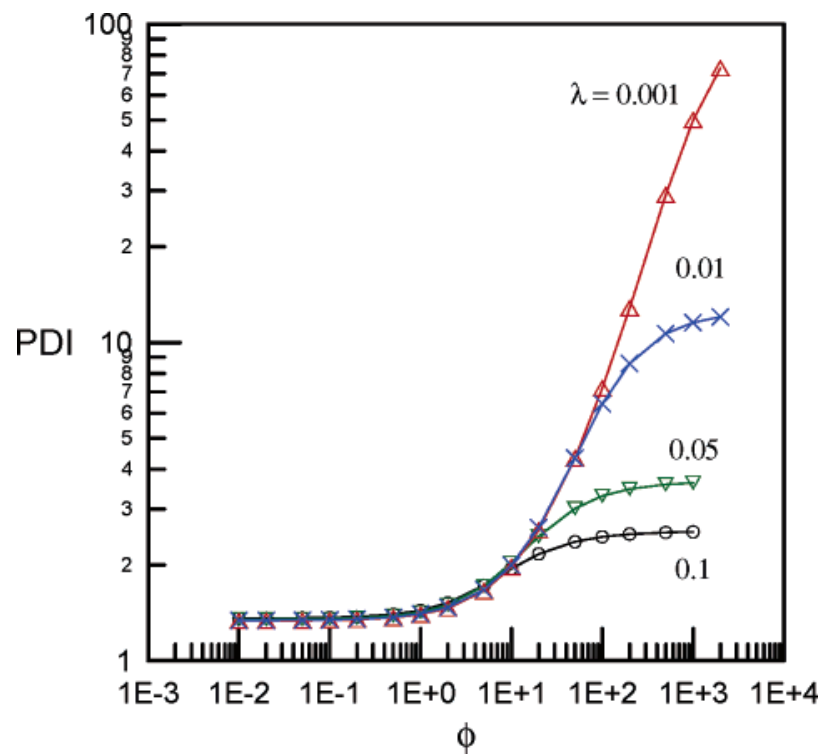

Figure 7. Dependence of the final PDI on feed rate, $\phi$, and core/monomer ratio, $\lambda$.

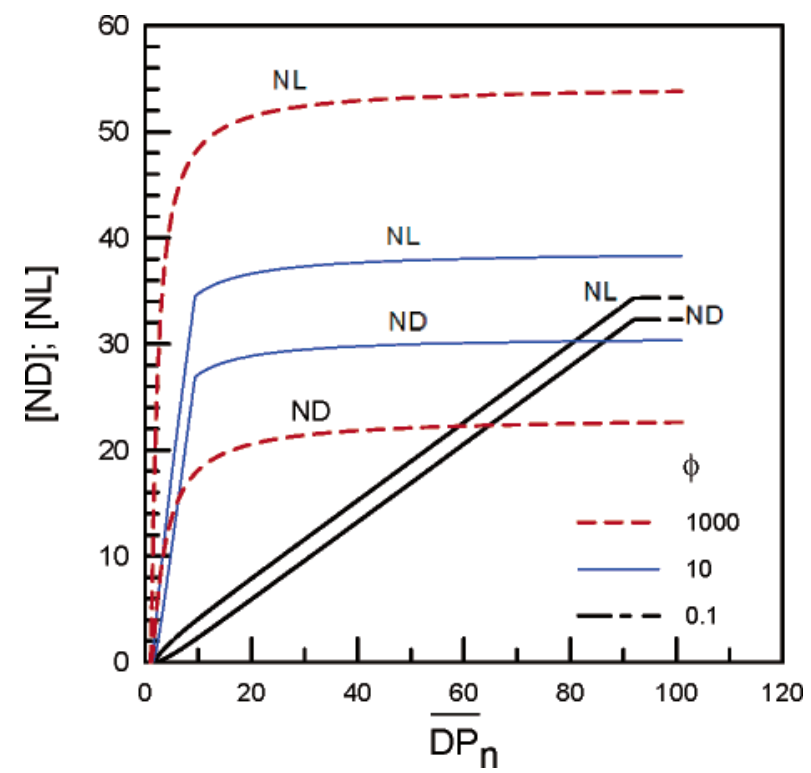

Figure 8. Changes of the number of linear and dendritic units during polymerization at various feed rates at $\lambda=0.01$, where $[\mathrm{ND}]=\mathrm{ND} / \mathrm{N}_{0}$ and $[\mathrm{NL}]=\mathrm{NL} / \mathrm{N}_{0}$.

branched polymers. ${ }^{29}$ Holter and Frey ${ }^{30}$ suggested a modified degree of branching, $\mathrm{DB}(\mathrm{HF})$. It is based on the actual number over the maximum possible number of dendritic units:

$$
\begin{aligned}
\mathrm{DB}(\mathrm{HF}) & =\frac{2 \mathrm{ND}}{2 \mathrm{ND}+\mathrm{NL}}= \\
& \frac{G(6)+G(10)}{G(6)+G(10)+0.5[G(4)+G(5)+G(9)]}
\end{aligned}
$$

where ND is the number of dendritic units and NL is the number of linear units.

The changes of the number of linear and dendritic units on the degree of polymerization under various feed rates are shown in Figure 8. The quick addition of $\mathrm{AB}^{*}$ monomers, $\phi=1000$, the NL is far larger than the ND

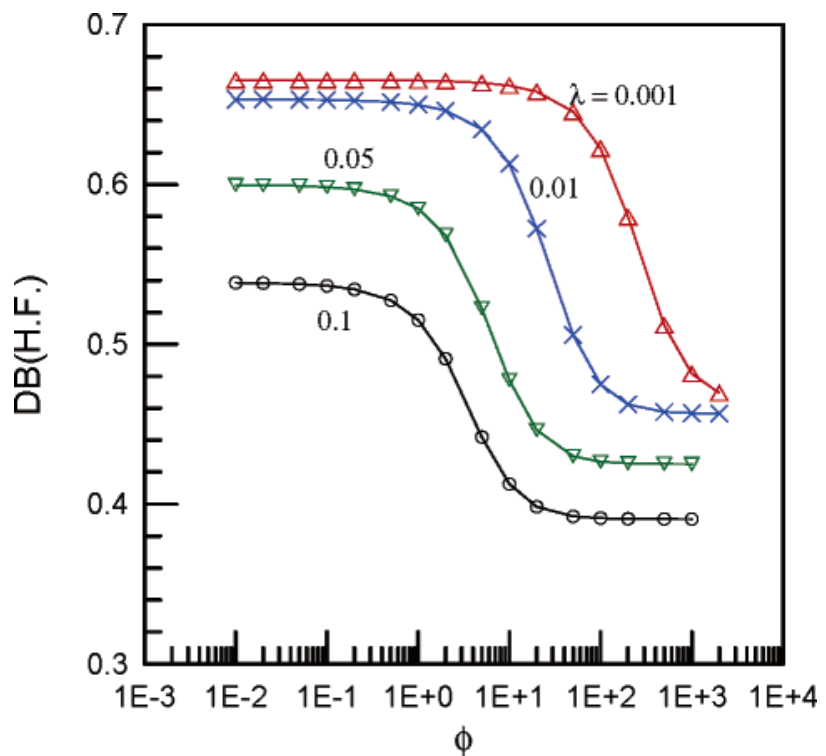

Figure 9. Dependence of the final $\mathrm{DB}(\mathrm{HF})$ on feed rate and core/monomer ratio $\lambda$.

during polymerization. It causes a lower degree of branching of the HBPs. On the contrary, at a low feed rate, $\phi=0.1$, the ND is very close to the NL, and the dendritic number also increases; thus, the degree of branching increases.

Increasing of the content of $\mathrm{C}_{3}$ * cores, the number of the dendritic units $\mathrm{G}(10), \mathrm{c}_{3}$, rises, but it is not sufficient to compensate for the reduction of unit $G(6)$, ab; therefore, the $\mathrm{DB}(\mathrm{HF})$ fall as $\mathrm{C}_{3}{ }^{*}$ cores increases. The dependences of the degree of branching, $\mathrm{DB}(\mathrm{HF})$, on the feed rate, $\phi$, and core/monomer ratio, $\lambda$, are plotted in Figure 9. For a low content of $\mathrm{C}_{3}{ }^{*}$ cores, for example at $\lambda=0.001$, and the parameter of feed rate $\phi$ is lower than 10 , a high $\mathrm{DB}(\mathrm{HF})$, about 0.66 , can be achieved. However, the $\mathrm{DB}(\mathrm{HF})$ of polymers decreases quickly to about 0.48 at $\phi=1000$, which is very close to that of batch system, 0.46 .

\section{Conclusion}

The generating function method have been applied to the self-condensing vinyl polymerization of multifunctional $\mathrm{C}_{3} *$ cores with $\mathrm{AB}^{*}$ monomers added slowly into the reactor. The final number-average degree of polymerization can be controlled by the core/monomer ratio and increases with the added $\mathrm{AB}^{*}$ monomers. It was found that, under slower addition (parameter of feed rate $\phi<2$ ), the polydispersity index can be achieved below 1.5. A high degree of branching, about 0.66 , can be achieved at $\phi$ lower than 10 and a low core/monomer ratio. For example, the hyperbranched polymers with high degree of polymerization of 1001, high degree of branching, $\mathrm{DB}(\mathrm{HF})=0.66$, and narrow $\mathrm{MWD}$, $\mathrm{PDI}=$ 1.46 , can be produced at $\lambda=0.001$ and $\phi$ lower than 2 in a semibatch reactor.

Acknowledgment. We thank the National Science Council, Taiwan, for the financial support of this study under Contract NSC-93-2120-M-002-011. 


\section{Appendix. Kinetic Schemes of the SCVP}

The reactions of SCVP between various structural units (not functional groups or molecules) can be summarized as following 16 kinetic schemes:

$$
\begin{aligned}
& \mathrm{AB}^{*}+\mathrm{AB}^{*} \stackrel{\mathrm{k}_{\mathrm{AB}^{*}}}{\longrightarrow} \mathrm{Ab}-\mathrm{A}^{*} \mathrm{~B}^{*} \quad \mathrm{G}(1)+\mathrm{G}(1) \stackrel{\mathrm{k}_{1}}{\longrightarrow} \mathrm{G}(3)+\mathrm{G}(2) \\
& \mathrm{AB}^{*}+\sim \mathrm{A}^{*} \mathrm{~B}^{*} \stackrel{\mathrm{k}_{\mathrm{AB}^{*}}}{\longrightarrow} \sim \mathrm{A}^{*} \mathrm{~b}-\mathrm{A}^{*} \mathrm{~B}^{*} \quad \mathrm{G}(1)+\mathrm{G}(3) \stackrel{\mathrm{k}_{2}}{\longrightarrow} \mathrm{G}(3)+\mathrm{G}(4) \\
& \mathrm{AB}^{*}+\succ \mathrm{aB}^{*} \stackrel{\mathrm{k}_{\mathrm{AB}} \mathrm{B}^{\longrightarrow}}{\longrightarrow} \succ \mathrm{ab}-\mathrm{A}^{*} \mathrm{~B}^{*} \quad \mathrm{G}(1)+\mathrm{G}(5) \stackrel{\mathrm{k}_{3}}{\longrightarrow} \mathrm{G}(3)+\mathrm{G}(6) \\
& \mathrm{AB}^{*}+\sim \mathrm{A}^{*} \mathrm{~B}^{*} \stackrel{\mathrm{k}_{\mathrm{A}^{*}}}{\longrightarrow} \mathrm{B}^{*} \mathrm{~A}^{*} \succ \mathrm{aB}^{*} \quad \mathrm{G}(1)+\mathrm{G}(3) \stackrel{\mathrm{k}_{4}}{\longrightarrow} \mathrm{G}(3)+\mathrm{G}(5) \\
& \mathrm{AB}^{*}+\sim \mathrm{A}^{*} \mathrm{~b} \sim \stackrel{\mathrm{k}_{\mathrm{A}^{*}}}{\longrightarrow} \mathrm{B}^{*} \mathrm{~A}^{*} \succ \mathrm{ab} \sim \mathrm{G}(1)+\mathrm{G}(4) \stackrel{\mathrm{k}_{5}}{\longrightarrow} \mathrm{G}(3)+\mathrm{G}(6) \\
& \mathrm{Ab} \sim+\mathrm{AB}^{*} \stackrel{\mathrm{k}_{\mathrm{AB}}{ }^{\circ}}{\longrightarrow} \mathrm{Ab}-\mathrm{A}^{*} \mathrm{~b} \sim \mathrm{G}(2)+\mathrm{G}(1) \stackrel{\mathrm{k}_{6}}{\longrightarrow} \mathrm{G}(4)+\mathrm{G}(2) \\
& \mathrm{Ab} \sim+\sim \mathrm{A}^{*} \mathrm{~B}^{*} \stackrel{\mathrm{k}_{\mathrm{AB}^{*}}}{\longrightarrow} \sim \mathrm{A}^{*} \mathrm{~b}-\mathrm{A}^{*} \mathrm{~b} \sim \mathrm{G}(2)+\mathrm{G}(3) \stackrel{\mathrm{k}_{7}}{\longrightarrow} \mathrm{G}(4)+\mathrm{G}(4) \\
& \mathrm{Ab} \sim+\succ \mathrm{aB}^{*} \stackrel{\mathrm{k}_{\mathrm{AB}^{*}}}{\longrightarrow} \succ \mathrm{ab} \sim \mathrm{A}^{*} \mathrm{~b} \sim \mathrm{G}(2)+\mathrm{G}(5) \stackrel{\mathrm{k}_{8}}{\longrightarrow} \mathrm{G}(4)+\mathrm{G}(6) \\
& \mathrm{Ab} \sim+\sim \mathrm{A}^{*} \mathrm{~B}^{*} \stackrel{\mathrm{k}_{\mathrm{A}^{*}}}{\longrightarrow} \sim \mathrm{bA}^{*} \succ \mathrm{aB}^{*} \quad \mathrm{G}(2)+\mathrm{G}(3) \stackrel{\mathrm{k}_{\mathrm{g}}}{\longrightarrow} \mathrm{G}(4)+\mathrm{G}(5) \\
& \mathrm{Ab} \sim+\sim \mathrm{A}^{*} \mathrm{~b} \sim \stackrel{\mathrm{k}_{\mathrm{A}^{*}}}{\longrightarrow} \sim \mathrm{bA}^{*} \succ \mathrm{ab} \sim \mathrm{G}(2)+\mathrm{G}(4) \stackrel{\mathrm{k}_{10}}{\longrightarrow} \mathrm{G}(4)+\mathrm{G}(6) \\
& \mathrm{AB}^{*}+\mathrm{C}_{3}^{*} \stackrel{3 \mathrm{k}_{\mathrm{AC}}}{\longrightarrow} \mathrm{C}_{2}^{*} \mathrm{c}-\mathrm{A}^{*} \mathrm{~B}^{*} \quad \mathrm{G}(1)+\mathrm{G}(7) \stackrel{\mathrm{k}_{\Perp}}{\longrightarrow} \mathrm{G}(3)+\mathrm{G}(8) \\
& \mathrm{AB}^{*}+\mathrm{C}_{2}^{*} \mathrm{c} \sim \underset{2 \mathrm{k}_{\mathrm{AC}}}{\longrightarrow} \mathrm{C}^{*} \prec \begin{array}{l}
\mathrm{c}-\mathrm{A}^{*} \mathrm{~B}^{*} \\
\mathrm{c} \sim
\end{array} \quad \mathrm{G}(1)+\mathrm{G}(8) \stackrel{\mathrm{k}_{12}}{\longrightarrow} \mathrm{G}(3)+\mathrm{G}(9)
\end{aligned}
$$

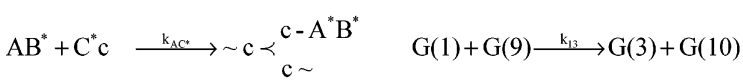

$$
\begin{aligned}
& \mathrm{Ab} \sim+\mathrm{C}_{3}^{*} \stackrel{3 \mathrm{k}_{\mathrm{AC}} *}{\longrightarrow} \mathrm{C}_{2}^{*} \mathrm{c}-\mathrm{A}^{*} \mathrm{~b} \sim \mathrm{G}(2)+\mathrm{G}(7) \stackrel{\mathrm{k}_{14}}{\longrightarrow} \mathrm{G}(4)+\mathrm{G}(8) \\
& \mathrm{Ab} \sim+\mathrm{C}_{2}^{*} \mathrm{c} \sim \underset{2 \mathrm{k}_{A c^{*}}}{\longrightarrow} \mathrm{C}^{*} \prec \underset{\mathrm{c} \sim}{\mathrm{c}-\mathrm{A}^{*} \mathrm{~b} \sim} \quad \mathrm{G}(2)+\mathrm{G}(8) \stackrel{\mathrm{k}_{15}}{\longrightarrow} \mathrm{G}(4)+\mathrm{G}(9) \\
& \mathrm{Ab} \sim+\mathrm{C}^{*} \mathrm{c} \sim \stackrel{\mathrm{k}_{\mathrm{AC}}}{\longrightarrow} \sim \mathrm{c} \prec \underset{\mathrm{c} \sim}{\mathrm{c}-\mathrm{A}^{*} \mathrm{~b} \sim} \mathrm{G}(2)+\mathrm{G}(9) \stackrel{\mathrm{k}_{16}}{\longrightarrow} \mathrm{G}(4)+\mathrm{G}(10)
\end{aligned}
$$

or

$$
\mathrm{G}\left(\mathrm{b}_{\mathrm{i} 1}\right)+\mathrm{G}\left(\mathrm{b}_{\mathrm{i} 2}\right) \stackrel{\mathrm{k}_{\mathrm{i}}}{\longrightarrow} \mathrm{G}\left(\mathrm{b}_{\mathrm{i} 3}\right)+\mathrm{G}\left(\mathrm{b}_{\mathrm{i} 4}\right) \quad \mathrm{i}=1,2, \ldots, 16
$$

in which

$$
\begin{aligned}
& \mathrm{G}(1)=\mathrm{AB}^{*} \text { monomer } \\
& \mathrm{G}(2)=\mathrm{Ab} \sim \\
& \mathrm{G}(3)=\sim \mathrm{A}^{*} \mathrm{~B}^{*} \\
& \mathrm{G}(4)=\sim \mathrm{A}^{*} \mathrm{~b} \sim \\
& \mathrm{G}(5)=\succ \mathrm{aB} \\
& \mathrm{G}(6)=\succ \mathrm{ab} \sim \\
& \mathrm{G}(7)=\mathrm{C}_{3}^{*} \text { core } \\
& \mathrm{G}(8)=\mathrm{C}^{*} \prec \mathrm{C}^{*} \\
& \mathrm{c}(9)=\mathrm{C}^{*}{ }_{\mathrm{c} \sim}^{\mathrm{c} \sim} \\
& \mathrm{G}(10)=\sim \mathrm{c} \prec{ }_{\mathrm{c} \sim}^{\mathrm{c} \sim}
\end{aligned}
$$

Furthermore, an example of the reaction between two isomers is shown as follows:

$A b-A^{*} B^{*}+B^{*} A^{*}-c \prec c-A^{*} B^{*} \underset{c-A^{*} B^{*}}{\stackrel{k_{7}\left(=k_{A^{*}}\right)}{\longrightarrow}}$

$$
\mathrm{B}^{*} \mathrm{~A}^{*}-b A^{*}-b A^{*}-\mathrm{c} \prec \begin{array}{r}
\mathrm{c}-\mathrm{A}^{*} \mathrm{~B}^{*} \\
\mathrm{c}-\mathrm{A}^{*} \mathrm{~B}^{*}
\end{array}
$$

then

$$
\begin{aligned}
& <\mathrm{E}^{\prime}>=\mathrm{Ab}-\mathrm{A}^{*} \mathrm{~B}^{*} \\
& <E^{\prime \prime}>=B^{*} A^{*}-c \prec^{c-A^{*} B^{*}}
\end{aligned}
$$

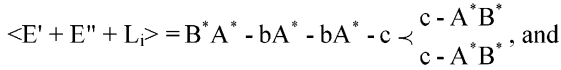

$$
\begin{aligned}
& E^{\prime}=(0,1,1,0,0,0,0,0,0,0,2) \\
& \mathrm{E}^{\prime \prime}=(0,0,3,0,0,0,0,0,0,1,4) \\
& \mathrm{L}_{7}=(0,-1,-1,+2,0,0,0,0,0,0,0) \\
& \mathrm{E}^{\prime}+\mathrm{E}^{\prime \prime}+\mathrm{L}_{3}=(0,0,3,2,0,0,0,0,0,1,6) \\
& \mathrm{k}_{7}=\mathrm{k}_{\mathrm{AB}} *
\end{aligned}
$$

\section{References and Notes}

(1) Uhrich, K. Trends Polym. Sci. 1997, 5, 388.

(2) Hult, A.; Johansson, M.; Malmstrom, E. Adv. Polym. Sci. 1999, 143,1 .

(3) Gao, C.; Yan, D. Prog. Polym. Sci. 2004, 29, 183.

(4) Voit, B. J. Polym. Sci., Part A: Polym. Chem. 2000, 38, 2505.

(5) Kim, Y. H. J. Polym. Sci., Part A: Polym. Chem. 1998, 36, 1685.

(6) Liu, H.; Nasman, J. H.; Skrifvars, M. J. Polym. Sci., Part A: Polym. Chem. 2000, 38, 3074.

(7) Nguyen, C.; Hawker, C. J.; Miller, R. D.; Huang, E.; Hedrick, J. L.; Gauderon, R.; Hilborn, J. G. Macromolecules 2000, 33, 4281.

(8) Sato, T.; Higashida, N.; Hirano, T.; Seno, M. J. Polym. Sci., Part A: Polym. Chem. 2004, 42, 1609.

(9) Chen, J.; Peng, H.; Law, C. C. W.; Dong, Y.; Lam, J. W. Y.; Williams, I. D.; Tang, B. Z. Macromolecules 2003, 36, 4319

(10) Bai, Y.; Song, N.; Gao, J. P.; Sun, X.; Wang, X.; Yu, G.; Wang, Z. Y. J. Am. Chem. Soc. 2005, 127, 2060.

(11) Kuchanov, S.; Slot, H.; Stroks, A. Prog. Polym. Sci. 2004, 29 , 563

(12) Frechet, J. M. J.; Henmi, M.; Gitsov, I.; Aoshima, S.; Leduc, M. R.; Grubbs, R. B. Science 1995, 269, 1080.

(13) Muller, A. H. E.; Yan, D.; Wulkow, M. Macromolecules 1997, 30, 7015 .

(14) Yan, D.; Muller, A. H. E.; Matyjaszewski, K. Macromolecules 1997, 30, 7024

(15) Radke, W.; Litvinenko, G. I.; Muller, A. H. E. Macromolecules 1998, 31, 239

(16) Yan, D.; Zhou, Z.; Muller, A. H. E. Macromolecules 1999, 32 , 245.

(17) Litvinenko, G. I.; Muller, A. H. E. Macromolecules 2002, 35, 4577.

(18) Simon, P. F. W.; Radke, W.; Muller, A. H. E. Macromol. Rapid Commun. 1997, 18, 865

(19) Simon, P. F. W.; Muller, A. H. E. Macromolecules 2004, 37 7548 .

(20) Sakamoto, K.; Aimiya, T.; Kira, M. Chem. Lett. 1997, 1245.

(21) Sunder, A.; Hanselmann, R.; Frey, H.; Mulhaupt, R. Macromolecules 1999, 32,4240 .

(22) Cheng, K.-C. Polymer 2003, 44, 877.

(23) Cheng, K.-C. Polymer 2003, 44, 1259

(24) Cameron, C.; Fawcett, A. H.; Hetherington, C. R.; Mee, R. A. W.; Mcbride, F. V. J. Chem. Phys. 1998, 108, 8235

(25) Dusek, K.; Somvarsky, J.; Smrokova, M.; Simonsick, Jr., W. J.; Wilczek, L. Polym. Bull. (Berlin) 1999, 42, 489.

(26) Burgath, A.; Sunder, A.; Frey, H. Macromol. Chem. Phys. $\mathbf{2 0 0 0}, 201,782$.

(27) Galina, H.; Szustalewicz, A. Macromolecules 1990, 23, 3833.

(28) Cheng, K.-C.; Wang, L. Y. Macromolecules 2002, 35, 5657.

(29) Hawker, C. J.; Frechet, J. M. J. J. Am. Chem. Soc. 1991, 113, 4583.

(30) Frey, H.; Holter, D. Acta Polym. 1999, 50, 67.

MA050640S 